\title{
Efficacy of Combination Therapy with rhTNFR:Fc and Methotrexate in the Patients with Disease-modifying Antirheumatic Drug -resistant Rheumatoid Arthritis
}

Fu Wen-yi, Zhang Ning and Yang Lili

Department of Rheumatology, Shengjing Hospital, China Medical University, Shengyang 110004, China

\begin{abstract}
Objective: To observe the efficacy of combining recombinant human tumour necrosis factor-Fc [rhTNFR:Fc ,etanercept] and methotrexate (MTX) in patients with disease-modifying antirheumatic drug (DMARD)-resistant rheumatoid arthritis

Methods: Collected 64 active RA patients with DMARD-resistant, according to patients' gender, age, duration and extent of disease activity, divided the 64 patients randomly into comparable two groups. The experimental group within thirty-two patients, were treated with twice-weekly subcutaneous etanercept $(25 \mathrm{mg})$ and meanwhile weekly oral MTX $(15 \mathrm{mg})$;the control group within thirty-two patients, were treated with daily oral prednisone $(5-10 \mathrm{mg})$ and meanwhile weekly oral MTX $(15 \mathrm{mg})$.Course of treatment is 12 weeks. Clinical response was assessed using American College of Rheumatology (ACR) criteria.
\end{abstract}

Result: As compared with patients received prednisone and MTX, patients received etanercept and MTX had a more significant improvement at ACR20 at 4th, 8th and 12th weeks $(P<0.05)$, and a more significant improvement at ACR50 at 4th, 8th and 12 th weeks $(P<0.05)$.

Conclusions: Compared to the traditional combination of MTX and low dose prednisone, etanercept combining MTX has a more significant efficacy in patients with DMARD-resistant rheumatoid arthritis.

Key words: rhTNFR:Fc; methotrexate; prednisone; arthritis; rheumatoid; clinical trial

Rheumatoid arthritis (rheumatoid arthritis, RA) is a chronic progressive systemic inflammatory disease, prevalence rate of Chinese is 0.32 percent to 0.36 percent, to $1 \%$ of the Western countries [1]. Tumor necrosis factor- $\alpha$ (TNF- $\alpha$ ) is an important physiological inflammatory mediators in the host-mediated inflammatory response, resulting in tissue damage plays an important role. RA patients with synovial immunohistochemistry analysis showed the existence of TNF- $\alpha$ in synovial lining cells, especially at the junction of cartilage and pannus [2]. RA patients after treatment, serum levels of TNF- $\alpha$ significantly decreased according to the same period improved arthritis index.Recombinant human tumor necrosis factor- $\alpha$ receptor II IgG FC fusion protein( rhTNFR: Fc) is a fusion protein producd using recombinant DNA technology,which can specific block the interactions between TNF- $\alpha$ and its receptor on the cell surface. Many clinical trials of rhTNFR: Fc abroad have confirmed the clinical efficacy in early RA, active RA patients and in patients with disease-modifying antirheumatic drug (DMARD)-resistant rheumatoid arthritis [3-6].This study is to observe the efficacy of combining rhTNFR:Fc and MTX in patients with DMARD-resistant rheumatoid arthritis .

\section{Information and Methods}

\section{Select case}

64 cases of patients were inpatients or outpatients selected from the department of rheumatology, Shengjing Hospital, China Medical University.

Selection criteria: (1)in line with the American Institute of Rheumatology in 1987 RA classification criteria; (2)the disease is active before medication (the judging index for activity is: a. joint swelling number $\geq$
6; b.number of joint tenderness $\geq 6$; c. The duration of morning stiffness $\geq 45 \mathrm{~min}$; d. erythrocyte sedimentation rate (ESR) $\geq 28 \mathrm{~mm} / \mathrm{lh}$ and / or C-reactive protein (CRP) $\geq 20 \mu \mathrm{g} / \mathrm{ml}$ ); (3) have undergone, including methotrexate (MTX), at least two anti-rheumatic drug (DMARD) treatment ,but the effect was not obvious.

Elimination criteria: (1) with severe heart, liver, kidney and blood, and other important organs disease, endocrine system disease and the history of those diseases; (2) pregnant women, breast-feeding women; (3) previously received biological agents (infliximab, etanercept, adalimumab) treatment; (4)being infected and / or with the high opportunity to be infected; (5) cancer patients or in the family of the susceptible population to tumor; (6)have undergone glucocorticoid in the last month.

Of the 64 patients, 56 cases are female, 8 cases are men; age 32 to 73 years old, the average age is 54.2 years old; course :24 to 96 months, average course:57.5 months. According to the patients gender, age, duration and extent of disease activity, were randomly divided into two groups comparable. Before test, patients were accounted for with common adverse drug reactions and possible adverse events, and obtained written informed consent, then identified as subjects.

*Corresponding author: Zhang Ning, Department of Rheumatology, Shengjing Hospital, China Medical University, Shengyang 110004, China, E-mail: cmuzn@tom.com

Received March 14, 2012; Accepted April 20, 2012; Published April 22, 2012

Citation: Wen-yi F, Ning Z, Lili Y (2012) Efficacy of Combination Therapy with rhTNFR:Fc and Methotrexate in the Patients with Disease-modifying Antirheumatic Drug -resistant Rheumatoid Arthritis. J Arthritis 2:104. doi:10.4172/2167-7921.1000104

Copyright: (C) 2012 Wen-yi F, et al. This is an open-access article distributed unde the terms of the Creative Commons Attribution License, which permits unrestricted use, distribution, and reproduction in any medium, provided the original author and source are credited. 
Citation: Wen-yi F, Ning Z, Lili Y (2012) Efficacy of Combination Therapy with rhTNFR:Fc and Methotrexate in the Patients with Disease-modifying Antirheumatic Drug -resistant Rheumatoid Arthritis. J Arthritis 1:104. doi:10.4172/2167-7921.1000104

\section{Medication method}

rhTNFR: Fc group of 32 patients were subcutaneous injected rhTNFR: Fc 2 times weekly,25mg / times, while oral MTX 15mg weekly; control group of 32 cases oral Pred Song $5 \sim 10 \mathrm{mg} / \mathrm{d}$ according to the circumstances, while oral MTX 15mg weekly. Two groups may choose a non-steroidal anti-inflammatory drugs orally, can be shifted to another if ineffective. All patients were observed for 12 weeks. For the first time in drug treatment and after 2, 4, 8 and 12 week follow-up.

\section{Observing index}

The patients in test group and control group,who were in the first time in drug treatment and after 2, 4, 8 and 12 week follow-up,were recorded index as following: number of swollen joints, number of tenderness joints, rest pain, activities of daily living, and the evaluation of doctors of overall disease situation, the evaluation of patients of overall disease situation, the sedimentation rate (ESR) and C-reactive protein (CRP).

\section{Therapeutic effect evaluation}

Using the criteria established by American Rheumatism Association :ACR20, ACR50 and ACR70. ACR20 is defined as patients with joint swelling and tenderness for the improvement of $20 \%$, and with $20 \%$ improvement at least 3 of 5 in the following: rest pain, activities of daily living, and the evaluation of doctors of overall disease situation, the evaluation of patients of overall disease situation, and CPR or ESR. ACR50, ACR70 apply the same standards were defined as $50 \%$ or $70 \%$ improvement.

\section{Adverse effect}

Record the adverse reactions occuring time, the severity, duration, the measures adopted, and the consequence, whether stoping the test or not.

\section{Statistical treatment}

Use SPSS13.0 statistical analysis software. Adopt 2-sided test, P $<0.05$, mean the difference was statistically significant. Two enumeration data is computed by pearson chi-square comparison test, or the continuity correction of chi-square test, according to the minimum expected count of the data. Compare the two measurement data, by two independent samples $t$ test.

\section{Result}

\section{General state of health}

64 patients join in the test, the test group and control group each have 32 cases; 62 cases of patients completed the tst, the test group of 31 cases, 31 cases in the control group, 1 case of test group withdrew, with Injection site reaction, 1 case of control group withdrew, with inefficacy. There was no significant difference between the two groups of patients before treatment of sex $(\mathrm{P}=0.704)$, age $(\mathrm{P}=0.364)$, duration $(\mathrm{P}$

\begin{tabular}{|l|l|l|l|}
\hline Group & $\begin{array}{l}\text { Test group } \\
(\text { mean } \pm \text { SD })\end{array}$ & $\begin{array}{l}\text { Control group } \\
(\text { mean } \pm \text { SD })\end{array}$ & P value \\
\hline Age(year) & $53.2 \pm 9.4$ & $55.3 \pm 8.6$ & 0.364 \\
\hline Duration(month) & $53.0 \pm 19.8$ & $61.9 \pm 19.4$ & 0.078 \\
\hline ESR $(\mathrm{mm} / \mathrm{h})$ & $59.2 \pm 12.1$ & $54.3 \pm 13.0$ & 0.135 \\
\hline CRP $(\mathrm{g} / \mathrm{l})$ & $57.1 \pm 13.6$ & $51.7 \pm 12.1$ & 0.104 \\
\hline
\end{tabular}

Levene's test for equality of variances: $P>0.05$.

Table 1: The information sheet of the test group and control group.
$=0.078), \operatorname{ESR}(\mathrm{P}=0.135)$ and $\mathrm{CRP}(\mathrm{P}=0.104)$. (Table 1$)$.

\section{Curative effect analysis}

The treatment of the first 2 weeks, the ACR20 response rate in the test group was $32.3 \%, 12.9 \%$ in the control group, but the difference was not statistically significant; the treatment of the first 4,8 and 12 weeks, ACR20 response rate in the test group were significantly higher than the control group $(\mathrm{P}<0.05)$ (Table 2). Treatment after 4, 8 and 12 weeks, ACR50 response rate in the test group were higher than the control group $(\mathrm{P}<0.05)$ (Table 3$)$. After the treatment in the first 2, 4 , 8 and 12 weeks, ACR70 in the the test group was higher than the control group, but the difference was not statistically significant $(\mathrm{P}>0.05)$ (Table 4).

\section{Adverse effect}

There were 3 cases of injection site reaction in the test group, of which 2 cases fade within 2 days, but the reaction remained if continue; 1 case of skin reaction gradually increased, which disappeared 1 week after after drug withdrawal(the patient has history of penicillin allergy). Which shows that we have to pay attention to the allergy of patients with a history of drug allergy in rhTNFR: Fc treatment.The respiratory tract infections have been occurred in both groups, in which 2 cases of the test group, 3 patients in the control group, who were elderly frail patients, there was no significant difference between the two groups $(\mathrm{P}>$ $0.05)$.

\section{Discussion}

Rheumatoid arthritis (RA) is a chronic progressive systemic inflammatory disease, without treatment, a small number of patients may achieve remission temporarily, most patients will have sustained synovitis, an increasing number of joint damage and disability, a few patients will progress rapidly. The mortality rate in RA patients is higher

\begin{tabular}{|l|l|l|l|l|}
\hline \multicolumn{1}{|c|}{ Group } & \multicolumn{4}{c|}{ ACR20 } \\
\cline { 2 - 5 } & $2^{\text {nd }}$ week & $4^{\text {th }}$ week & $8^{\text {th }}$ week & $12^{\text {th }}$ week \\
\hline Test group & $32.3 \%$ & $45.2 \%$ & $54.8 \%$ & $64.5 \%$ \\
\hline Control group & $12.9 \%$ & $16.1 \%$ & $19.4 \%$ & $22.6 \%$ \\
\hline P value & 0.068 & 0.013 & 0.004 & 0.001 \\
\hline
\end{tabular}

Table 2: the percentage of patients achieving ACR20 in the experimental and the control group.

\begin{tabular}{|l|l|l|l|l|}
\hline \multicolumn{1}{|c|}{ Group } & \multicolumn{4}{c|}{ ACR50 } \\
\cline { 2 - 5 } & $2^{\text {nd }}$ week & $4^{\text {th }}$ week & $8^{\text {th }}$ week & $12^{\text {th }}$ week \\
\hline Test group & $9.7 \%$ & $19.4 \%$ & $32.3 \%$ & $38.7 \%$ \\
\hline Control group & $0 \%$ & $0 \%$ & $0 \%$ & $3.2 \%$ \\
\hline P value & $0.237^{\text {a }}$ & $0.032^{\text {b }}$ & 0.001 & 0.001 \\
\hline
\end{tabular}

a. The minimum expected count is 1.50

b. The minimum expected count is 3.00 .

Table 3: the percentage of patients achieving ACR50 in the experimental and the control group.

\begin{tabular}{|l|l|l|l|l|}
\hline \multicolumn{1}{|c|}{ Group } & \multicolumn{4}{c|}{ ACR70 } \\
\cline { 2 - 6 } & $2^{\text {nd }}$ week & $4^{\text {th }}$ week & $8^{\text {th }}$ week & $12^{\text {th }}$ week \\
\hline Test group & $6.5 \%$ & $9.7 \%$ & $12.9 \%$ & $19.4 \%$ \\
\hline Control group & $0 \%$ & $0 \%$ & $0 \%$ & $3.2 \%$ \\
\hline P value & $0.472^{\text {a }}$ & $0.237^{\text {b }}$ & $0.121^{\text {c }}$ & $0.108^{\text {d }}$ \\
\hline
\end{tabular}

a. The minimum expected count is 1.00 .

b. The minimum expected count is 1.5 .

c. The minimum expected count is 2.00 .

d. The minimum expected count is 3.5. Choose Fisher's Exact Test.

Table 4: the percentage of patients achieving ACR70 in the experimental and the control group. 
than the general population. Effective treatment for patients with RA can reduce joint damage, disability, and even death. However, the general treatment can not stop the progress of the disease, only a few drugs can be used to relieve the progress of the disease, but the effect is limited and which can not eliminate the severe toxic reactions.

TNFalpha accelerated inflammatory responses by down-regulating heme oxygenase 1 (HO-1) expression in human monocytes. TNF antagonists may block this TNF-dependent suppression of HO-1 expression, resulting in an amelioration of inflammation [7].TNF decreases HLA-DR expression by reducing CIITA mRNA levels in myeloid cells, functionally resulting in a decreased capacity of myeloid cells to stimulate $\mathrm{T}$ cells. Concordantly, ameliorating disease activity in chronic inflammatory diseases by neutralizing TNF restores expression of HLADR on myeloid cells as well as the ability of myeloid cells to stimulate T cells [8]. As compared with oral methotrexate, subcutaneous etanercept acted more rapidly to decrease symptoms and slow joint damage in patients with early active rheumatoid arthritis[5]. TNF blockers are recommended for the treatment of active RA, generally after an adequate trial of another effective DMARD, of which methotrexate (MTX) is a commonly used example. They have also been used successfully with other DMARDs. TNF blocking agents can be added to pre-existing therapy, or, when appropriate, may replace previous DMARDs. There is evidence that TNF blockers are effective for the treatment of RA in MTX naive patients [9].

In the past, RA patients with ineffective DMARD therapy may be given low-dose hormone, but the effect is limited, and even if $5 \sim 10 \mathrm{mg}$ / d of prednisone, long-term application is also inevitably lead to osteoporosis, and other adverse reactions. With the birth of the anti-TNF agents, we have carried out a number of study with anti-TNF agents in the treatment of refractory RA. In a period of 3 years of doubleblind trials, 549 cases of RA patients with ineffective DMARD therapy were injected rhTNFR: Fc $25 \mathrm{mg}$, twice weekly. After 3 years of treatment ACR20, ACR50 and ACR70 achieved 78\%, 51\% and 27\%; and found that the treatment of the most common adverse reactions including upper respiratory tract infection, influenza-like syndrome, rash and injection-site reactions [10]. In a 7 years clinical observation, 714 cases of patients with an annual incidence of serious adverse events was $14.8 / 100$ patients, annual serious infection rate was $4.2 / 100$ patients, the rate of cancer each year was $1.0 / 100$ patients, the mortality rate was 0.7 per year / 100 patients [6]. Adverse reactions of application of long-term rhTNFR: Fc was similar to patients with RA reported. Which prompted application of long-term rhTNFR: Fc earnings ratio remains higher.

Today, large-scale clinical trials have confirmed that rhTNFR: Fc united MTX treatment of active RA is better, which have the same effect in RA patients with ineffective DMARD therapy reported abroad. Patients with active rheumatoid arthritis taking MTX >or $=12.5 \mathrm{mg} /$ week for $>$ or $=3$ months were included in the 16 week, randomised, open-label study. Patients were randomly assigned to either ETN (25 $\mathrm{mg}$ subcutaneous injection twice weekly) added to the baseline dose of MTX or ETN monotherapy. 315 patients were randomised to ETN (n $=160)$ or ETN plus MTX $(\mathrm{n}=155)$. The rates of adverse and serious adverse events were similar between the treatment groups. Both the addition of ETN to MTX and the substitution of ETN for MTX in patients with rheumatoid arthritis who had an inadequate response to MTX resulted in substantial improvements in clinical signs and symptoms and were generally well-tolerated treatment strategies for improving clinical signs and symptoms of rheumatoid arthritis [11]. A randomized, double-blind two-year clinical trial confirmed: Etanercept in combination with MTX reduced disease activity, slowed radiographic progression, and improved function more effectively than did either monotherapy over a 2-year period. No increase in toxicity was associated with combination treatment with etanercept plus MTX [12]. 1,161 cases of Patients with active rheumatoid arthritis, not responding to at least two DMARDs including MTX starting etanercept or infliximab therapy for the first time, were included in a structured clinical follow-up protocol. Cox regression models showed that the risk for premature treatment termination of patients treated with infliximab was threefold higher than for etanercept $(\mathrm{p}<0.001)$. The regression analysis showed that patients receiving concomitant MTX had better treatment continuation than patients treated solely with TNF blockers $(\mathrm{p}<0.001)$. Moreover, patients receiving concomitant MTX had superior drug survival than patients receiving other concomitant DMARDs $(\mathrm{p}<0.010)$ [13].

This study compared the effect between low-dose prednisone (5 $10 \mathrm{mg} / \mathrm{d}$ ) combined MTX and rhTNFR: Fc combined MTX for the patients with DMARD-resistant rheumatoid arthritis. The results showed that: in the first 2 weeks after treatment, part of the patients of both groups achieved ACR20, However, there was no significant statistically difference. After the treatment of 8 and 12 weeks, ACR2 0 and ACR50 of rhTNFR: Fc group were significantly higher than that of the prednisone group $(\mathrm{P}<0.05)$. Which hinted that rhTNFR: Fc combined MTX and MTX combined low-dose hormone may be improved the inflammatory response in a part of patients, and following the treatment, significantly, rhTNFR: Fc combined MTX was more effective than low-dose hormone combined MTX. However, the ACR70 of the two groups had no significant significant statistically difference in the period, which may be related to the limited time to observe, the limited sample, and other factors. And in the control group, only 1 patient in the first 12 weeks achieved ACR70, proved that the treatment of low-dose hormone plus MTX made a limited effect.

According to foreign reports, the most common adverse reactions of rhTNFR: Fc were the injection site reactions and infections [14-15]. There were 3 cases of injection site adverse reactions in the study, 2 of which vanished in 2 days, but the reactions can appear again if continuentur remedia. 1 case of skin reactions gradually increased, which disappeared 1 week after exiting from the drug tests. There were 2 cases respiratory tract infections occurred in the 32 cases of patients in rhTNFR: Fc group, which can not exclude that the drug may increase the possibility of infection. In addition, anti-TNF antibody therapy may increase the risk of serious infection and cancer [16]. No malignant tumors was found in patients in the study. It has been reported anti-TNF therapy may increase the risk of tuberculosis [17], no new TB-fat was found in this study.

Overview, for the patients of DMARD-resistant rheumatoid arthritis, rhTNFR: Fc combined MTX comparing to the low-dose hormone plus MTX has better efficacy and safety. However, patients were divide into two groups according to gender, age, duration and extent of disease in this study, and with the limited sample size, it can not rule out other factors that influencing the outcome of treatment-induced bias. The efficacy and safety of rhTNFR: Fc combined MTX for the treatment of DMARD-resistant active RA, yet may be further studied in large sample of the double-blind, randomized controlled trials or meta-analysis of high-quality.

\section{References}

1. Hochberg MC. (1981) Adult and juvenile rheumatoid arthritis:current epidemiologic concepts[J]. Epidemiol Rev 3: 27-44.

2. Maini RN, Brennan FM, Williams R, Chu CQ, Cope Ap,et al. (1993) TNF-alpha 
Citation: Wen-yi F, Ning Z, Lili Y (2012) Efficacy of Combination Therapy with rhTNFR:Fc and Methotrexate in the Patients with Disease-modifying Antirheumatic Drug -resistant Rheumatoid Arthritis. J Arthritis 1:104. doi:10.4172/2167-7921.1000104

in rheumatoid arthritis and prospects of anti-TNF thrapy[J]. Chin Exp Rheumatol 8: S173-S175

3. Moreland LW, Schiff MH, Baumgartner SW, Tindall EA, Fleischmann,et al. (1999) Etanercept therapy in rheumatoid arthritis: a randomized ,controlled trial. Ann Inte Med 130: 478-486.

4. Nanda S, Bathon JM. (2004) Etanercept: a clinical review of current and emerging indications. Expertop Pham acother 5: 1175-1186.

5. Bathon JM, Martin RW, Fleischmann RM, Tesser JR, SchiffMH,.et al.(2000) A comparison of etanercept and methotrexate in patients with early rheumatoid arthritis. N Engl J Med 343: 1586-1593.

6. Moreland LW, Weiblatt ME, Keystone EC, Kremer JM, Martin RW,et al. (2006) Etanercept treatment in adults with established rheumatoid arthritis 7 years of clinical experience. J Rheumatol 33: 854-861.

7. Kirino Y, Takeno M, Murakami S, Kabayashi M, Miura Ket al. (2007) Tumor necrosis factor alpha acceleration of inflammatory responses by down-regulating heme oxygenase 1 in human peripheral monocytes . Arthritis Rheum 56: 464475.

8. Mueller RB, Skapenko A, Grunke M,Wendler J,Stuhlmuller B,et al . (2005) Regulation of myeloid cell function and major histocompatibility complex class II expression by tumor necrosis factor . Arthritis Rheum. 52: 451-460.

9. Furst DE, Breedveld FC, Kalden JR,et al. (2004) Updated consensus statement on biological agents, specifically tumour necrosis factor alpha (TNFalpha) blocking agents and interleukin-1 receptor antagonist (IL-1ra),for the treatment of rheumatic diseases. Ann Rheum Dis, ,63: ii2-ii12.

10. Klareskog L, Gaubitz M, Rodriguez-Valverde V,et al. (2006) A long-term, openlabel trial of the safety and efficacy of etanercept (Enbrel) in patients with rheumatoid arthritis not treated with other disease-modifying antirheumatic drugs .65: 1578-1584.
11. Van Riel PL, Taggart AJ, Sany J, Gaubitz M, Nab HW,et al.(2006) Efficacy and safety of combination etanercept and methotrexate versus etanercept alone in patients with rheumatoid arthritis with an inadequate response to methotrexate: the ADORE study . Ann Rheum Dis 65: 1478-1483.

12. Van der Heijde D, Klareskog L, Rodriguez-Valverde V,et al. (2006) Comparison of etanercept and methotrexate, alone and combined, in the treatment of rheumatoid arthritis: two-year clinical and radiographic results from the TEMPO study, a double-blind, randomized trial . Arthritis Rheum 54: 1063-1074.

13. Kristensen LE, Saxne T, Nilsson JA, Geborek P (2006) Impact of concomitant DMARD therapy on adherence to treatment with etanercept and infliximab in rheumatoid arthritis. Results from a six-year observational study in southern Sweden. Arthritis Res Ther 8: R174.

14. Weinblatt ME, Kremer JM, Bankhurst A, Bulpitt KJ, Fleischmann,et al(1999) A trial of etanercept:a recombinant tumor necrosis factor receptor:Fc fusion protein in patients with rheumatoid arthritis receving methotrexate. New Engl Med 340: 253-259.

15. Elliot MJ, Maini RN, Feldmann M, Kalden JR, Antoni C (1994) Randomized double bland comparison of chimeric monoclonal antibody to tumor necrosis factor (cA2)versus placebo in rheumatoid arthritis. Lancet 344: 1105-1110.

16. Bongartz T, Sutton AJ, Sweeting MJ, Buchan I, Matteson EL,et al. (2006) AntiTNF antibody therapy in rheumatoid arthritis and the risk of serious infections and malignancies: systematic review and meta-analysis of rare harmful effects in randomized controlledtrials. JAMA 295: 2275-2285.

17. Askling J, Fored CM, Brandt L, Baeckelund E,Bertils son,et al. (2005) Risk and case characteristics of tuberculosisin rheumatoid arthritis associated with tumor necrosis factor antagonists in Sweden Arthritis Rheum 52: 1986-1992. 